\title{
Dossiê: Psicologia dialógica
}

\author{
Maria Claudia Lopes de Oliveira ${ }^{a^{*}}$ \\ Danilo Silva Guimarães ${ }^{b^{*}}$ \\ aUniversidade de Brasília, Instituto de Psicologia. Brasília, DF, Brasil \\ bUniversidade de São Paulo, Instituto de Psicologia. São Paulo, SP, Brasil
}

O tema que integra os artigos apresentados nesse número temático da Psicologia USP sobre a psicologia dialógica, traduz uma perspectiva interdisciplinar que vem se desenvolvendo ao longo das últimas duas décadas como um paradigma crítico. As concepções de dialogicidade que viabilizaram a emergência dessa perspectiva, em psicologia, têm suas origens na filosofia da linguagem de Bakhtin, nas psicologias sociais de James e Mead, e na psicologia histórica e sociocultural de Vygotsky. Concepções selecionadas desses autores têm sido contemporaneamente articuladas em um intenso debate com a filosofia fenomenológica de Merleau-Ponty, Lévinas e a hermenêutica gadameriana. Considera-se como um marco importante desse desenvolvimento a publicação do trabatho intitulado The dialogical self: beyond individualism and rationalism, de Hubert Hermans, Harry Kempen e Rens Van Loon, pela revista American Psychologist, em 1992. Neste trabalho são apresentadas elaborações críticas sobre a concepção cartesiana de sujeito, caracterizada como individualista e racionalista, e é analisado o impacto dessa visão sobre o pensamento ocidental.

No que se refere à influência do modelo cartesiano sobre a psicologia contemporânea, os autores ajustam o foco sobre o tema da personalidade, apontando o predomínio de perspectivas que tomam a unidade psicológica como uma estrutura isolada, autorreferenciada e racional. Em lugar desse modelo, os autores propuseram a noção de Self dialógico, em que a personalidade é definida como um sistema dual, no qual as funções psicológicas estão ancoradas na corporeidade, cujos aspectos cognitivos são interdependentes dos emocionais e a pessoa se constitui em íntima troca com a sociocultura. $\mathrm{O}$ artigo de 1992 potencializou o desenvolvimento de diversas pesquisas sobre a dialogicidade no Self, e, nesse contexto, a teoria do Self dialógico tem sido transformada, passando a acomodar não apenas $o$ interesse no desenvolvimento da personalidade, mas nas relações dialógicas em geral, o que inclui tanto as relações entre pessoas e comunidades, instituições e culturas como parte da dialogicidade intrínseca ao Self.

\section{História e fundamentos epistemológicos da psicologia dialógica:}

A partir da segunda metade do século XX, identificou-se entre diferentes vertentes das ciências sociais e

\footnotetext{
* Bolsistas de produtividade em pesquisa do $\mathrm{CNPq}$ (protocolos número 310848/2013-0 e 306563/2013-4, respectivamente).

Endereço para correspondência: claudia@unb.br
}

humanas uma guinada epistemológica no que concerne à abordagem dos fenômenos psicossociais. Tal guinada representou um conjunto de tentativas de romper com as visões científicas predominantes, no cenário das quais o homem havia sido fragmentado, tomado tal como um objeto natural, separado do contexto e neutralizado em seus aspectos subjetivos. Em suma, no intuito de se aproximar de critérios positivistas de cientificidade, uma parte expressiva das ciências humanas e sociais contribuiu para eliminar a subjetividade da psicologia.

As novas expressões do pensamento crítico divergem da ênfase predominantemente nomotética, realista e objetivista identificada na trajetória de desenvolvimento epistemológico das ciências. Parte da psicologia, como sistema de práticas profissionais e disciplina científica, não ficou indiferente às perspectivas críticas e, paulatinamente, fortaleceu sua sensibilidade às epistemologias que buscavam novas interpretações para o humano, a exemplo das feministas, pós-estruturalistas, construcionistas e materialista-dialéticas. Esses são exemplos de perspectivas em que a imagem individualista, universalista e despolitizada do homem é paulatinamente deslocada, cedendo lugar para um olhar relacional, culturalista e semiótico, em que se toma o ser humano na sua integralidade e evita-se todas as formas de reducionismo. Em suma, o desenvolvimento do pensamento crítico em psicologia teve como motor a busca pela recuperação de uma imagem forte da pessoa como um ser ativo, social, histórico e político que se forma e transforma em meio a práticas sociais concretas.

Deve-se salientar, no entanto, que a psicologia não se modificou de maneira global à luz das epistemologias críticas. Por ser uma ciência diversa e plural, ao lado de subáreas nas quais prosperaram teorias inspiradas em tais epistemologias, a exemplo da psicologia social, tem-se um conjunto de outras em que a teorização e as práticas de pesquisa se mantêm alinhadas, ainda hoje, com o modelo científico positivista tradicional.

O movimento crítico produziu um renovado interesse por temas da insipiente psicologia do século XIX, correspondente ao período em que esta começava a se tornar uma disciplina independente da Filosofia - tais quais o debate sobre a relação entre o conhecimento nomotético e idiográfico, a generalidade de processo e de resultado, a relação entre afeto e cognição, a cultura pessoal e cultura coletiva e a questão da alteridade. Não se trata, entretanto, de um simples retorno ao passado, pois, ao mesmo tempo o pensamento crítico em Psicologia acolhe avanços teóricos e metodológicos na compreensão de processos de significação, discursos e representações 
sociais - temas esses que estão na fronteira entre o subjetivo e o social.

Assim, temos em conta que a psicologia dialógica insere-se entre as perspectivas inovadoras desenvolvidas no final do século passado, o que tem representado um grande valor gerativo de ideias na contemporaneidade. Seus importantes desdobramentos teórico-metodológicos encontram-se em diferentes contextos de inserção da ciência psicológica. De modo esquemático, é possível identificar duas grandes tradições de estudos que convergem para a construção do paradigma dialógico da forma como podemos compreendê-lo nos dias atuais: um que provém dos estudos de linguagem e outro que provém da própria psicologia.

No que se refere à primeira abordagem, destacam-se os filósofos e teóricos da linguagem interessados na língua em uso, nos contextos cotidianos. Tinham interesse de estudar a linguagem evitando o viés reducionista identificado em abordagens que a representam como um dispositivo formal, abstrato e artificial (das quais seria exemplo o estruturalismo de Saussure). Nessa perspectiva, tais pensadores adotam o diálogo, as interações e situações comunicativas concretas como seu objeto de estudo. A comunicação aqui não se confunde com a mera transmissão de informação; define-se como processo triádico, que envolve, no mínimo, dois interlocutores em interação mediada por signos. No caso, as transações semióticas são enfatizadas e abordadas em estreita relação com diferentes fenômenos e constituem, a um só tempo, um contexto para as interações humanas, uma ferramenta cultural que organiza tais interações na forma de sistemas particulares de comunicação e, ainda, podem ser tomadas como as próprias unidades de análise dos fenômenos humanos, quando se coadunam com uma perspectiva relacional.

Dentre os pensadores dessa abordagem, destacam-se por sua importância histórica para o desenvolvimento da psicologia dialógica nomes como Bakhtin e Charles S. Peirce. Para esses autores, o diálogo não se reduz a um mero objeto de estudo, e sim representa uma metáfora para interpretar os fenômenos humanos, quando se coloca como aspecto central dessa interpretação a natureza relacional/interativa/ comunicativa dos fenômenos. Em outras palavras, a qualidade dialógica se aplica às interações e transações humanas. Igualmente, constitui um modelo compreensivo para o funcionamento intrapsíquico: nesse modelo, a subjetividade não seria mais compreendida como unidade, mas como multiplicidade de posições sociais internalizadas.

No que se refere à psicologia, incluem-se aqui as matrizes que contribuíram para uma visão não individualista, essencialista ou autocontida, que contribui para forjar uma concepção de subjetividade que é interdependente da alteridade. Nesse segundo grupo, é possível incluir autores como Willian James e George Herbert Mead, que enfatizam a particularidade do Selfe da identidade pessoal como imbricada no todo social, destacando o papel da psicologia na compreensão das relações concretas da pessoa com outras pessoas e com o mundo. Mais recentemente, na esteira deles, reconhece-se hoje uma pluralidade de influências teórico-epistemológicas originárias do que chamamos psicologia dialógica, oriundas de campos que vão da filosofia às ciências humanas e sociais, passando pelas ciências da saúde, comunicação, literatura, artes e arquitetura. Essas influências têm contribuído sobremaneira para a constituição de uma área de pesquisa e prática profissional em psicologia diversa e plural.

\section{Psicologia dialógica: perspectivas e desdobramentos atuais}

Adotar a perspectiva dialógica no enfoque dos fenômenos psicológicos implica em consequências epistemológicas importantes, que não podem passar despercebidas. A primeira delas é a assunção de íntima interdependência entre o nível pessoal e o social. A constituição pessoal é compreendida como processo na fronteira com o social (Lopes de Oliveira, 2013) e, nessa medida, o que contribui para o desenvolvimento individual também afeta, em maior ou menor medida, o desenvolvimento social, contribuindo para o avanço cultural da humanidade e vice-versa. Portanto, o desenvolvimento subjetivo é visto como resultado de relações sociais internalizadas (Fávero, 2005; Zittoun \& Perret-Clermont, 2009).

Uma segunda característica marcante da abordagem dialógica é a ênfase depositada na relação de interdependência Eu-Outro, que resulta no processo denominado "separação inclusiva" (Valsiner \& Cairns, 1992). Ao passo que cada pessoa é uma unidade relativamente autônoma em relação ao outro, cada um se constitui nas dinâmicas trocas intersubjetivas estabelecidas em cenários sociais. $\mathrm{O}$ Outro, o não-Eu e a alteridade são dimensões centrais dentro de uma abordagem dialógica (Simão, 2010; Simão \& Valsiner, 2007). A outridade pode ser compreendida como outra pessoa real (por exemplo, este com quem se conversa) e se fazer presente em processos intrapsicológicos (como a lembrança dos argumentos ou opiniões desenhadas por um interlocutor que não está mais presente e que, ainda assim, toma parte na construção de sentido); como outro imaginário ou idealizado (um ser mítico, ou uma versão mítica de um outro real). Também pode ser representada por um grupo social, ou ainda, por dispositivos simbólicos que medeiem a coconstituição de um fenômeno psicológico, partindo da tensão dialógica entre Eu-Mim-Outro.

A alteridade, por sua vez, permanece como aquilo do outro e de si mesmo que escapa a uma apreensão compreensiva. Um excedente de sentido e significação que permanece como motor das ações humanas na direção de produzir uma resposta ética, capaz de assegurar a possibilidade contínua de interlocução entre diferentes.

A abordagem dialógica é coerente com perspectivas integrativas, que evitam fracionar o fenômeno em partes ou elementos. As interpretações conduzidas buscam incluir, sistematicamente, todas as facetas envolvidas em um fenômeno, entre as quais a social, cultural, afetiva e cognitiva. Da mesma forma, tem-se reconhecido apreço por metodologias investigativas, interpretativas e hermenêuticas, além 
de estudos de corte idiográfico, por meio dos quais busca-se alcançar sistemas explicativos contextualizados que se desdobrem em um conhecimento generalizável aberto a novos estudos de caso (Valsiner, 2012). A generalidade de processo que se espera emergir da metodologia hermenêutica se distingue, portanto, da generalidade de resultado, dado que o resultado dos processos dialógicos são sempre situados e alcançados por meio de trajetórias que acontecem em tempo irreversível.

Um empreendimento científico dialógico considera que o contato das pessoas particularizadas com o mundo real é sempre mediado por signos, via de regra, no contexto da atividade social que serve de quadro de referência para os processos semióticos. Os processos de significação e a negociação de significados dão-se em uma arena ideológica, de acordo com Bakhtin (1988), ou semiosfera, na perspectiva de Lotman (1990). Em outras palavras, a construção do conhecimento é compreendida como a reconstrução pessoal de signos sociais, sendo o produto de uma relação reflexivo-interpretativa na qual o sujeito cognoscente, o objeto a ser conhecido e o Outro estão intimamente relacionados e culturalmente ancorados. Tal aspecto informa sobre a dinamicidade da vida relacional e a complexidade inerente à adoção de uma abordagem epistemológica claramente dialógica.

Encontra-se, entre os estudos desenvolvidos na perspectiva da psicologia dialógica, um especial interesse pelo que se refere ao tema do Self. A estruturação intrapsíquica da experiência que leva à emergência de um senso de si continuado na linha do tempo, ao mesmo tempo único e interdependente dos contextos histórico, social e cultural específicos, é um tema recorrente (Andacht \& Michel, 2005; Michel, Andacht \& Gomes, 2008; Lopes de Oliveira, 2003, 2006, 2013; Guimarães, 2013). Entretanto, não se deve confundir esse interesse com um retorno às perspectivas monistas e objetivantes da subjetividade. A unicidade da pessoa é vista como se constituindo, na linha do tempo, a partir das relações dialógicas estabelecidas tanto no jogo social, interpsíquico, como no âmbito intrapsíquico. Esse aspecto dá origem a uma unidade que é, ao mesmo tempo, múltipla.

Com este número temático, buscamos reunir e discutir trabalhos de pesquisadores que vêm desenvolvendo reflexões no campo do dialogismo teórico-metodológico em psicologia, articulando outras áreas na fronteira com a psicologia (como a pedagogia, a literatura, a linguística, a filosofia, a antropologia, a sociologia etc.). Os artigos trazem objetos de estudo empiricamente definidos para, a partir deles, desenvolver concepções centrais da área que impliquem a reconfiguração das formas de se abordar temas e processos investigados.

Esperamos que as ideias presentes neste número da Psicologia USP sejam disparadoras de novas e instigantes reflexões sobre tópicos clássicos da psicologia, vistos aqui sob uma perspectiva ainda pouco conhecida entre os psicólogos brasileiros. Desejamos, desse modo, contribuir com o avanço conceitual da nascente psicologia dialógica no Brasil.

\section{Referências}

Andacht, F., \& Michel, M. (2005). A semiotic reflection on self-interpretation and identity. Thoery \& Psychology, 15(1), 51-75.

Bakhtin, M. (1988). Marxismo e filosofia da linguagem. São Paulo, SP: Hucitec.

Fávero, M. H. (2005). Desenvolvimento psicológico, mediação semiótica e representações sociais: por uma articulação teórica e metodológica. Psicologia: teoria e pesquisa, 21(1), 17-25.

Guimarães, D. S. (2013). Self and dialogical multiplication. Interacções, 24(9), 214-242.

Hermans, H. J. M., Kempen, H. J. G., \& Van Loon, R. J. P. (1992). The dialogical self: beyond individualism and rationalism. American Psychologist, 47(1):23-33.

Lopes de Oliveira, M. C. S. (2003). Subjetividade e conhecimento: do sujeito da representação ao sujeito dialógico. Fractal - Revista do Departamento de Psicologia da UFF, 15(2), 33-52.

Lopes de Oliveira, M. C. S. (2006). Identidade, narrativa e desenvolvimento na adolescência: uma revisão crítica. Psicologia em Estudo, 11(2), 427-436.

Lopes de Oliveira, M. C. S. (2013). The Bakhtinian self and beyond: towards a dialogical phenomenology of the self. Culture \& Psychology, 19(2), 259-272.

Lotman, Y.(1990). The universe of the mind: a semiotic approach to culture. Bloomington, IN: Indiana University Press.
Michel, M., Andacht, F., \& Gomes, W. (2008). The relevance of secondness to the psychological study of the dialogical self. International Journal for Dialogical Science, 3(1), 301-334.

Simão, L. M. (2010). Ensaios Dialógicos; compartilhamento e diferença nas relações eu-outro. São Paulo, SP: Hucitec.

Simão, L. M., \& Valsiner, J. (2007). General conclusions: multiple faces of otherness within the infinite labyrinths of the self. In L. M. Simão \& J. Valsiner (Orgs.), Otherness in question: Labyrinths of the self (pp. 393-406). Charlotte, NC: Information Age.

Valsiner, J. (2012). Fundamentos de psicologia cultural: mundos da mente, mundos da vida. Porto Alegre, RS: Artmed.

Valsiner, J., \& Cairns, R. B. (1992). Theoretical perspectives on conflict and development. In C. U. Shantz \& W. W. Hartup (Eds.), Conflict in child and adolescent development (pp. 15-35). Cambridge, UK: Cambridge University Press.

Zittoun, T., \& Perret-Clermont, A.-N. (2009). Four social psychological lenses for developmental psychology. European Journal for Psychology of Education, 24(2), 387-403. 